\title{
Perbandingan Indeks Massa Tubuh Pada Pasien Hipertensi Dengan Tekanan Darah Yang Terkontrol dan Tidak Terkontrol di RSUD Arifin Achmad Provinsi Riau
}

\author{
Eka Bebasari, $^{1 *}$ Dimas Pramita Nugraha ${ }^{2}$
}

\begin{abstract}
The nutritional status is a factor that related with blood pressure. The nutritional status that indicated by body mass index (BMI) needs to be considered in management of hypertension. This study was a cross-sectional analytic that assess relationship between BMI and hypertension controlled. The subjects of the study were hypertension patients that visit outpatient clinic of Arifin Ahmad General Hospital, Riau Province. Datas were analyzed by unpaired t-test. The results showed that patients with obesity grade 1 were more frequent in controlled hypertension group compared to uncontrolled hypertension (43.8\% vs $32.5 \%$ ). The BMI average in patients with controlled hypertension group was 24.2, while in uncontrolled hypertension group was 24.8 ( $\mathrm{p}>0.05)$. There was no statistically significant difference between BMI in both groups patients.
\end{abstract}

Keywords: Body Mass Index, hypertension, control

Tekanan darah yang tidak terkontrol merupakan faktor risiko untuk terjadinya penyakit jantung koroner, gagal jantung, stroke, dan gagal ginjal. Manajemen terapi dalam menurunkan tekanan darah yang efektif akan menurunkan risiko kematian maupun insiden yang tidak fatal. ${ }^{1-4}$

Banyak faktor yang mempengaruhi pengontrolan tekanan darah, diantaranya faktor obat seperti golongan antihipertensi yang digunakan, monoterapi atau terapi kombinasi, faktor kepatuhan (compliance) penggunaan antihipertensi, faktor motivasi dan dukungan keluarga, faktor tingkat pengetahuan pasien, tingkat stres, faktor kebiasaan, nutrisi dan status gizi berlebih (obesitas). ${ }^{4,5}$

Kegemukan (obesitas) merupakan ciri khas dari populasi hipertensi, jantung orang yang mengalami obesitas harus bekerja lebih keras untuk memompakan darah agar dapat menggerakkan beban berlebih dari tubuh tersebut. Untuk mengetahui seeorang memiliki berat badan berlebih atau tidak adalah dengan menghitung indeks massa tubuh (IMT) atau body mass index (BMI). ${ }^{6}$

Penelitian Pasiah menunjukkan bahwa rerata tekanan darah pada orang obesitas baik pria maupun wanita lebih tinggi 5,8\% dari pada orang yang tidak obesitas. Obesitas juga meningkatkan risiko penyakit kardiovaskular dan serebrovaskular. ${ }^{6}$

\section{METODE}

Penelitian ini adalah penelitian cross-sectional dengan menilai indeks massa tubuh (IMT) menggunakan tinggi dan berat badan dari data rekam medis pasien hipertensi di RSUD Arifin Ahmad Provinsi Riau. Populasi pada penelitian ini adalah pasien rawat jalan yang didiagnosis menderita hipertensi. Sampel dalam penelitian ini diambil dengan metode accidental sampling. Data dianalisis dengan analisis bivariat uji t tidak berpasangan. Indeks Massa tubuh (IMT) diukur dengan rumus

\footnotetext{
Corresponding Author : ekabebasari@gmail.com

KJF Fisiologi Universitas Riau

KJF Farmakologi Universitas Riau
} 
Adapun klasifikasi IMT menurut kriteria Asia Pasifik terdapat pada tabel 1.

Tabel 1. Klasifikasi IMT menurut kriteria Asia Pasifik

\begin{tabular}{ll}
\hline \multicolumn{1}{c}{ Klasifikasi berat badan } & IMT $(\mathrm{Kg} / \mathrm{m})^{2}$ \\
\hline Berat badan kurang & $<18,5$ \\
Berat badan normal & $18,5-22,9$ \\
Berat badan lebih & $23-24,9$ \\
Obesitas derajat 1 & $25-29,9$ \\
Obesitas derajat 2 & $=30$ \\
\hline
\end{tabular}

Tekanan darah yang terkontrol adalah tekanan darah $<140 / 90 \mathrm{mmHg}$ selama paling kurang 3 bulan untuk usia $<60$ tahun dan tekanan darah $<150 / 90$ mmHg selama paling kurang 3 bulan untuk usia $\geq 60$ tahun. Tekanan darah yang tidak terkontrol adalah tekanan darah $\geq 140 / 90 \mathrm{mmHg}$ dalam 3 bulan untuk usia $<60$ tahun dan tekanan darah $\geq 150 / 90 \mathrm{mmHg}$ dalam 3 bulan untuk usia $\geq 60$ tahun.

Tabel 2. Distribusi Karakteristik Pasien Hipertensi

\section{HASIL}

Distribusi karakteristik subjek penelitian terdapat pada tabel 2. Tampak dari tabel bahwa dari 96 pasien sebagian besar berusia $\geq 60$ tahun $(61,5 \%)$ dengan proporsi jumlah wanita sebanding dengan pria. Pasien dengan obesitas grade 1 memiliki persentase paling besar $(35,4 \%)$ dibandingkan kelompok IMT yang lain. Sebagian besar pasien hipertensi tekanan darahnya tidak terkontrol (83,3\%).

\begin{tabular}{cc}
\hline \multicolumn{1}{c}{ Karakteristik } & Jumlah (\%) \\
$\mathrm{N}=96$ \\
\hline Usia : & \\
$-\quad \geq 60$ tahun & $59(61,5)$ \\
$-\quad<60$ tahun & $37(38,5)$ \\
Jenis kelamin : & $54(56,2)$ \\
$-\quad$ Wanita & $42(43,8)$ \\
$-\quad$ Pria & $4(4,2)$ \\
IMT : & $28(29,2)$ \\
- Berat Badan Kurang & $20(20,8)$ \\
- Berat Badan Normal & $34(35,4)$ \\
- Overweight & $10(10,4)$ \\
- Obesitas Grade 1 & $16(16,7)$ \\
$-\quad$ Obesitas Grade 2 & $80(83,3)$ \\
Tekanan Darah : & Terkontrol
\end{tabular}

Tabel 3 menunjukkan bahwa pada pasien hipertensi dengan tekanan darah terkontrol, kelompok pasien dengan obesitas grade 1 memiliki persentase terbanyak $(43,8 \%)$, demikian juga pada pasien dengan tekanan darah tidak terkontrol $(32,5 \%)$. 
Tabel 3. IMT Pada Pasien Hipertensi dengan Tekanan Darah Terkontrol dan tidak Terkontrol

\begin{tabular}{lcc}
\hline IMT & Terkontrol & Tidak Terkontrol \\
& $\mathrm{N}=16(\%)$ & $\mathrm{N}=80(\%)$ \\
\hline Berat Badan Kurang & $1(6,2)$ & $3(3,8)$ \\
Berat Badan Normal & $3(18,8)$ & $25(31,2)$ \\
Overweight & $4(25)$ & $16(20)$ \\
Obesitas Grade 1 & $7(43,8)$ & $27(32,5)$ \\
Obesitas Grade 2 & $1(6,2)$ & $9(11,2)$ \\
\hline
\end{tabular}

Uji t tidak berpasangan menunjukkan bahwa rerata IMT kelompok tekanan darah yang terkontrol $(24,21)$ dibandingkan kelompok dengan tekanan darah yang tidak terkontrol $(24,8)$ tidak berbeda bermakna ( $>00,05)$ (Tabel 4).

Tabel 4 .Uji t

\begin{tabular}{lcc}
\hline \multicolumn{1}{c}{ IMT } & Mean & Nilai p \\
\hline Tekanan Darah Terkontrol & 24,21 & $\mathrm{p}=0,589$ \\
\hline Tekanan Darah Tidak terkontrol & 24,8 & \\
\hline
\end{tabular}

\section{PEMBAHASAN}

Sebagian besar pasien hipertensi berusia $\geq 60$ tahun $(61,5 \%)$. Hal ini dikarenakan selama proses pertambahan usia terjadi penurunan kelenturan pembuluh darah sehingga kecenderungan untuk terjadinya hipertensi meningkat. Tetapi saat ini dengan terjadinya perubahan gaya hidup, memungkinkan usia muda juga dapat menderita hipertensi. ${ }^{7,10}$

Proporsi penderita hipertensi berdasarkan jenis kelamin relatif sebanding antara laki-laki dan wanita, dimana wanita pada penelitian ini memiliki presentase sedikit lebih tinggi. Hasil ini berbeda dengan penelitian Ramadhani di Rumah Sakit Umum Pusat Nasional (RSUPN) Ciptomangunkusumo yang menunjukkan bahwa sebagian besar penderita hipertensi adalah laki-laki. Secara umum dikatakan bahwa kecenderungan kejadian hipertensi lebih banyak pada perempuan, tetapi prevalensi hipertensi berdasarkan jenis kelamin di beberapa populasi menunjukkan pola yang berbeda-beda. ${ }^{12,14}$

Sebagian besar pasien memiliki tekanan darah yang tidak terkontrol, hasil ini berbeda dengan penelitian Ramadhani di RSCM yang menunjukkan proporsi pasien hipertensi dengan tekanan darah terkontrol sebanding dengan yang tidak terkontrol. Hasil ini berbeda kemungkinan dikarenakan kriteria tekanan terkontrol yang di gunakan berbeda. Pada penelitian ini seorang dikatakan memiliki tekanan darah yang terkontrol jika selama tiga bulan memiliki tekanan darah yang normal $(<140 / 90 \mathrm{mmHg}$ untuk usia $<60$ tahun dan $<150 / 90 \mathrm{mmHg}$ untuk usia $\geq 60$ tahun), sedangkan pada penelitian Ramadhani hanya satu kali pengukuran. ${ }^{13,14}$

Hasil penelitian menunjukkan bahwa nilai rerata IMT pasien dengan tekanan darah terkontrol adalah 24,2, sedangkan nilai rerata IMT pasien dengan tekanan darah tidak terkontrol 24,8 ( $>>0,05)$. Hal ini menunjukkan baik kelompok tekanan darah yang terkontrol maupun tidak terkontrol memiliki nilai rerata IMT dengan kriteria berat badan berlebih (overweight) namun sudah mendekati obesitas menurut klasifikasi IMT Asia Pasifik. Hasil ini tidak berbeda jauh dengan penelitian di RSUP Kandou di Manado dimana sebagian besar pasien memiliki IMT yang overweight. ${ }^{10,12}$

Status IMT yang berlebih, menjadi salah satu prediktor yang dapat menyebabkan peningkatan tekanan darah sistolik dan diastolik sehingga hal ini akan mengakibatkan terjadinya hipertensi pada seseorang. Studi dari Framingham menunjukkan bahwa kenaikan berat badan $10 \%$ dapat meningkatkan tekanan darah $6 \mathrm{mmHg}$ dalam populasi yang besar. ${ }^{13.14}$ 
Berat badan berlebih dan obesitas merupakan ciri khas dari populasi hipertensi, jantung orang obesitas harus bekerja keras untuk memompakan darah agar bisa menggerakkan beban berlebih dari tubuh. Berat badan berlebih berhubungan dengan peningkatan tekanan darah pada orang dewasa maupun anak-anak. Menurunkan berat badan memiliki korelasi yang kuat dengan penurunan tekanan darah pada individu yang obesitas. ${ }^{7,814}$

Pengukuran tekanan darah yang rutin dan berkala pada pasien hipertensi sangat penting dilakukan untuk mengetahui apakah pasien termasuk hipertensi dengan tekanan darah terkontrol atau tidak terkontrol serta untuk mencegah atau mengurangi komplikasi pada pasien hipertensi. Faktor- faktor yang dapat memperberat terjadinya komplikasi perlu juga di pantau dan diperbaiki seperti berat badan, tinggi badan, lingkar pinggang, asupan garam, aktivitas fisik, dan gaya hidup. ${ }^{11,14}$

\section{KESIMPULAN}

Tidak ada perbedaan yang bermakna secara statistik antara IMT pasien dengan tekanan darah terkontrol dan pasien dengan tekanan darah tidak terkontrol.

\section{DAFTAR PUSTAKA}

1. World Health Organization. Data and statistics hypertension. http://www.who.int/topics/ cardiovascular_diseases/en/.Diakses pada 26 Juli .2009 .

2. Departemen Kesehatan Republik Indonesia. Profil Kesehatan Propinsi Riau 2012. http:// www.depkes.go.id. Diakses pada 28 Januari 2016

3. Hoer A, Gothe H, Schiffhorst G, Vincze G, and Hausler B. Persistence and adherence with antihypertensive drug therapy in a german sickness fund population. J Hum Hypertens. . 2007.21: $744-6$
4. Howland RD and Mycek MJ. Lippincott's lllustrated Reviews: Phamacology, Thid Edition. Lippincot Williams\& WilkinsB, Baltimore.2006.

5. The Seventh Report of the Joint National Committee on prevention, detection, evaluation, and treatment of high blood pressure.. NIH publication. 03 - 5233.2003

6. Saifullah. Pengaruh minum kopi terhadap terjadinya hipertensi di Kabupaten Tanggamus Provinsi Lampung. [Tesis]. Yogyakarta. 2007.

7. Taylor RB. A Handbook cardiovascular disease. Springer Sciences. New York 2005.

8. Finkel. Ilustrated Pharmacology. Lipincott. 2008.

9. James PA. Evidence-based guideline for the management of high blood pressure in adults report from the panel members appointed to the eighth joint national committee (JNC 8). JAMA. 2014;311(5):507-520

10. Bray GA and Bouchard C. Handbook of Obesity. 2nd ed. Marcel Dekkel Inc. New York. 2005.

11. Yuniati EE. Perbedaan asupan zat gizi dan status gizi pada usia lanjut hipertensi terkendali dan tidak terkendali di Panti Sosial Tresna Werdha Unit Abiyoso Yogyakarta. [Skripsi]. 2007

12. Dien NG, Mulyadi, Kundre RM. Hubungan indeks massa tubuh (IMT) dengan tekanan darah pada penderita hipertensi di Poliklinik Hipertensi dan Nefrologi BLU RSUP Prof .DR.R.D Kandou Manado. [Skripsi]. 2014

13.Fikriana R. Faktor-faktor yang diduga menjadi prediktor terjadinya peningkatan tekanan darah sistolik pada penderita hipertensi. Mesencephalon Jurnal Kesehatan. 2016.

14. Ramadhani AD. Hubungan kontrol tekanan darah dengan indeks massa tubuh pada pasien Hipertensi. [Skripsi]. Jakarta. 2013. 